\title{
Comparison of 2 recommendations for adjusting the working height in milking parlors
}

\author{
Martina C. Jakob*1 and Falk Liebers† \\ *Leibniz Institute for Agricultural Engineering and Bioeconomy, D-14469 Potsdam, Germany \\ †Federal Institute of Occupational Health and Safety (BAuA), D-10137 Berlin, Germany
}

\begin{abstract}
Milking cows is one of the major labor inputs on dairy farms. Modern parlors allow upright working positions, but pain and disorders among parlor workers are still very prevalent. The platform height in the parlors is important for the body posture of the workers. Based on a large set of data containing parlorspecific measures, anthropometrics, and bovimetrics, a simulation of 2 recommendations published in the literature was carried out. This article presents and discusses the results of 2 formulas for determining the appropriate pit depth. The shoulder and body height of the worker and the distance between the udder and the floor influence the adjustment of the pit depth. If work at shoulder level is favored, autotandem parlors offer the most suitable pit depths, whereas side-by-side parlors are too deep in all cases. Due to the variation in anthropometrics and bovimetrics, a good parlor design can reduce the extent of unfavorable body postures, but more technical measures are necessary to completely eliminate them. Actions that reduce the workload and the prevalence of musculoskeletal pain and disorders should be considered.
\end{abstract}

Key words: musculoskeletal symptom, milker, working height, parlor design

\section{INTRODUCTION}

Milking cows is one of the major work tasks on dairy farms. With increasing farm sizes come organizational changes such as task specialization. Milking cows, a job formerly rich in variety, is slowly changing into a monotonous occupation. Large farms never stop running: cows are milked 2 to 3 times per day every day.

Pain and disorders among milking parlor workers are very common, and the situation has not changed even though the workplace has improved (Pinzke, 2003,

Received September 23, 2016.

Accepted March 30, 2017.

${ }^{1}$ Corresponding author: mjakob@atb-potsdam.de
2016). In modern separate milking parlors, the worker is usually located lower than the cows and, consequently, no longer kneels or squats next to the animal. Carrying weight such as milk buckets is also no longer necessary. This improvement is significantly reducing the workload (Auernhammer, 1987). Nevertheless, a long-term study from Sweden (Pinzke, 2016) shows that pain and disorders among dairy workers are not reduced when systems change from tie stalls to loose housing. Recent surveys from Germany, the United States, Sweden, and Switzerland reveal that between 7 and 9 out of 10 workers who frequently milk cows have pain in different body parts, mainly the lower back, shoulders, and neck (Pinzke, 2003, 2016; Douphrate et al., 2009, 2014; Kauke et al., 2010; Lunner Kolstrup, 2012; Thinius and Jakob, 2014; Lunner Kolstrup and Jakob, 2016). Females are affected significantly more often (Pinzke, 2003, 2016; Lunner Kolstrup, 2012; Thinius and Jakob, 2014; Lunner Kolstrup and Jakob, 2016). Sweden and Germany report the highest prevalence (Thinius and Jakob, 2014; Lunner Kolstrup and Jakob, 2016). Lunner Kolstrup and Jakob (2016) found a significant association between herd size and the yearly prevalence of musculoskeletal symptoms in the shoulders, elbows, and feet. The Swedish farms held just under 100 cows on average, whereas the German sample ranged from 44 to 1,600 cows. Farms incorporated in the study of Douphrate et al. (2014) from the United States were much bigger, ranging from 680 to 6,000 dairy cows. Masci et al. (2016) report higher muscular load in the upper limbs for large US dairy farms $(2,200$ cows) compared with Italian farms (an average of 360 cows). The studies assessing pain and disorders used the Standardised Nordic Questionnaire (Kuorinka et al., 1987) to estimate the amount of musculoskeletal symptoms. Analyses of German sick leave data show that female milkers are at 2- to 5 -fold increased relative risk of taking sick leave compared with office workers due to the following diagnoses: mononeuropathies (e.g., carpal tunnel syndrome), enthesiopathies (e.g., tennis elbow), inflammation and swelling of a tendon or tendon sheets of the upper extremities, and knee disorders. Male milkers have an increased risk of sick leave due to 
enthesiopathia of the upper extremities (Liebers et al., 2016).

Accepted risk factors that may cause musculoskeletal symptoms and disorders in the upper extremities are awkward postures, high muscular load, repetitive movements, or manual work (da Costa and Vieira, 2010), all of which are characteristic of milking parlor work. Back pain is one of the most frequent symptoms in all countries (Eurofound, 2012). Lifting and awkward postures are associated with back disorders (da Costa and Vieira, 2010).

It is a basic approach in ergonomics to consider anthropometric characteristics of the workforce in workplace design (DIN/ISO, 2016). General guidelines for ergonomic design of sitting work and standing work are available (ISO, 2002) but are not easily applicable to the specific work process of preparing the udder and attaching the milking cluster. Nevertheless, some guidelines (i.e., ISO, 2000; DIN/ISO, 2009) should be followed, such as avoiding placing tools or items above shoulder height, positioning without overstretching, and avoiding bending while reaching down. Very few and rather general remarks are found for proper adjustment of floor heights in milking parlors. ÖKL-Arbeitskreis Landwirtschaftsbau (2015) recommends adjusting the cluster attachment to the shoulder height of the worker. In the literature, the description regarding the appropriate height of adjustable floors is vague; authors use the terms correct and convenient to support the decision, but exact measures are lacking. Jakob et al. (2012) described the influence of different working heights on kinematics, muscular activity, self-perceived exertion, heart rate, and process duration for the process of cluster attachment. That study investigated a range of $30 \mathrm{~cm}$ in the variation of udder height; $0 \mathrm{~cm}$ was the teat end at shoulder level, and task variations set the teat end at $15 \mathrm{~cm}$ above and below shoulder level. After a final ranking of the assessed parameters (e.g., kinematics, muscular load), the authors recommended working at shoulder level, where the overall load was lowest. In another study, Cockburn et al. (2015) tried to evaluate and quantify the workload for different parlor types by measuring body postures using a set of worn movement sensors. The resulting working height is defined by a coefficient based on the milker's body height, the floor level, and the cow's udder height. However, limitations of both approaches have to be considered. Jakob et al.'s (2012) recommendation to work at shoulder height in milking parlors is based on a laboratory study with a clearly defined but reduced set of working conditions and a wide set of psychophysiological outcomes. The recommendation given by Cockburn et al. (2015) was derived from a large data set that included a large variation of working heights. Working conditions in this field study were uncontrolled, and individual outcome parameters were not used to describe the psychophysiological responses.

Vos (1974) stated more than 4 decades ago that the pit depth is of great importance for maintaining an upright position during activities at the udder. He pointed out that standardization is impossible, but pit depth depends on cow size and the height of the milkers. The elbow should not hit the pit edge, so the pit edge must be lower than the elbows.

Thinius and Jakob (2014) carried out a precise workplace analysis to picture the reality on German dairy farms and to estimate the workload by measuring the amount of work at, above, and below shoulder level. Bovimetrics, including the vertical distance between the udder base and floor as well as the horizontal distance between the center of the claw bowl and the pit edge, were assessed during a normal milking period (Figure 1).

A range of up to $50 \mathrm{~cm}$ between the lowest and highest udder is typical on German dairy farms that milk Holstein Friesian cows (Table 1). The age of the cows influences the height of the udder and its size (Graf, 2005). In Germany, cows are milked for an average of less than 3 lactations (Martens and Bange, 2013). The range between different pit depths in the whole sample of the different milking parlors was $30 \mathrm{~cm}$. The lowest parlor, a rotary, had a platform height of $75 \mathrm{~cm}$, whereas the deepest pit measured $105 \mathrm{~cm}$ in a side-byside parlor (for details, see Table 1). Douphrate et al. (2014) reported pit depths about $10 \mathrm{~cm}$ deeper than the German parlors. On the other hand, the mainly Hispanic workforce of that sample is shorter and has a shorter grip reach compared with the average stated in DIN/ISO (2005; Table 2). Finally, a parlor needs to be adjusted to the anthropometrics of the workers (Vos, 1974). The range between a small female and a tall male is another $30 \mathrm{~cm}$ (shown in Table 2). For now, the only technical support for adjusting the working height is an adjustable floor, which can add up to around 80 $\mathrm{cm}$ in variation. However, even though the pit floor depth is adjustable, unfavorable situations for the workers still exist. Consequently, different settings occur, such as work below, at, and above shoulder level. Each of these settings induces typical kinematic patterns (Jakob et al., 2012) for the different body parts. Small changes have a measurable effect but no visible effect (Jakob et al., 2012). The weight of the milking cluster has a significant effect on the perceived strain, heart rate, electromyogram, and kinematics of the worker. No studies have focused on the effect of the horizontal distance between cluster and worker, which is another variable influencing the workload. Jakob et al. (2012) had a fixed distance of $40 \mathrm{~cm}$. Thinius and Jakob (2014) 
found a large variation within parlors when measuring the horizontal distance for each cow during a random milking period; values were significantly lower for the parallel or side-by-side parlors (Table 1). In many cases, the measured horizontal distance between the udder and the pit edge exceeded the net reach of a person (Table 2). Females are more often affected because their arms are shorter compared with men. To reach the udder, bending and stretching or twisting becomes unavoidable.

The following simulation using real data aims to discuss the differences between 2 recommendations available for determining the proper pit depth. In consequence, farmers will have support in choosing the appropriate pit depth if they own an adjustable floor or are installing a new parlor.

\section{MATERIALS AND METHODS}

\section{Data Sets}

To meet the aim of simulating working heights, knowledge of farm characteristics is necessary. A large set of cow biometric data (e.g., udder-floor distance), farm characteristics (e.g., number of milkers, herd size), and ergonomic data of the different parlors (e.g., milk- ing places per farm, pit depth, horizontal distance) is at our disposal, which allows us to simulate settings of 4 different parlor types taking into account the distribution of human body dimensions defined in DIN/ ISO (2005). Twenty-two German farms with more than 10,000 cows in lactation were visited, and workplace design was measured during a normal milking period.

The data set (Table 1) includes different parlor types such as autotandem (7\%), herringbone $30^{\circ}(32 \%)$, parallel (also called side-by-side parlors; 18\%), and inside rotaries (42\%). Figure 1 shows the measurement of vertical distance between the udder base and the floor (left) and the horizontal distance between the center of the claw bowl and the pit edge (right).

\section{Recommendations for Adjustment of Pit Floor Height}

In the literature, 2 recommendations for the adjustment of the working height in milking parlors recently have been published. Formula A, for calculating the optimized pit depth (OptiPD), was provided by Jakob et al. (2012), and formula B, called the milking health formula (MHF), was published by Cockburn et al. (2015). These 2 existing calculations include the following terms:

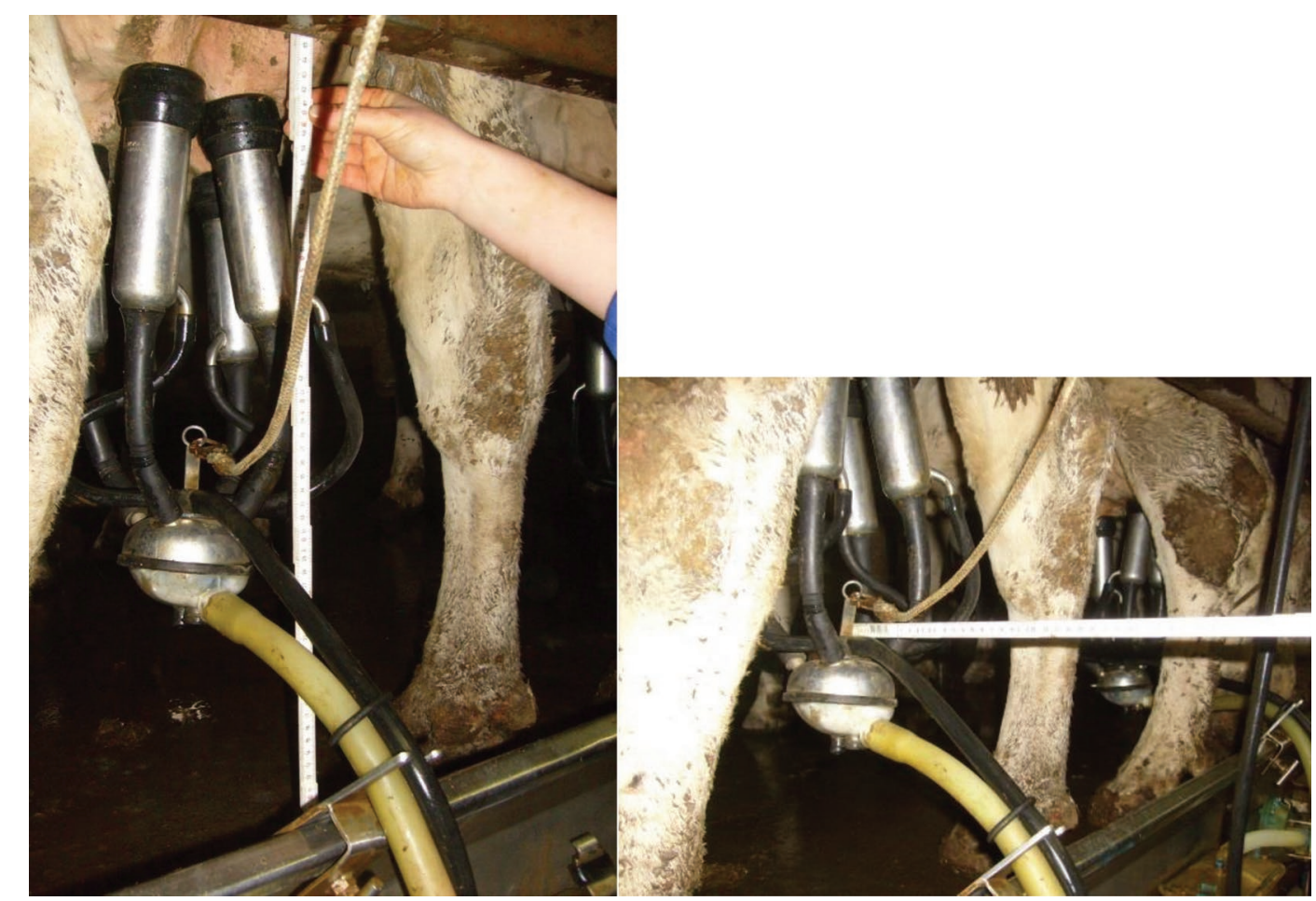

Figure 1. Procedure and measurement of the vertical distance between the udder base and the floor (left) and the horizontal distance between the center of the claw bowl and the pit edge (right). Color version available online. 
Table 1. Characteristics of farms with different parlor types

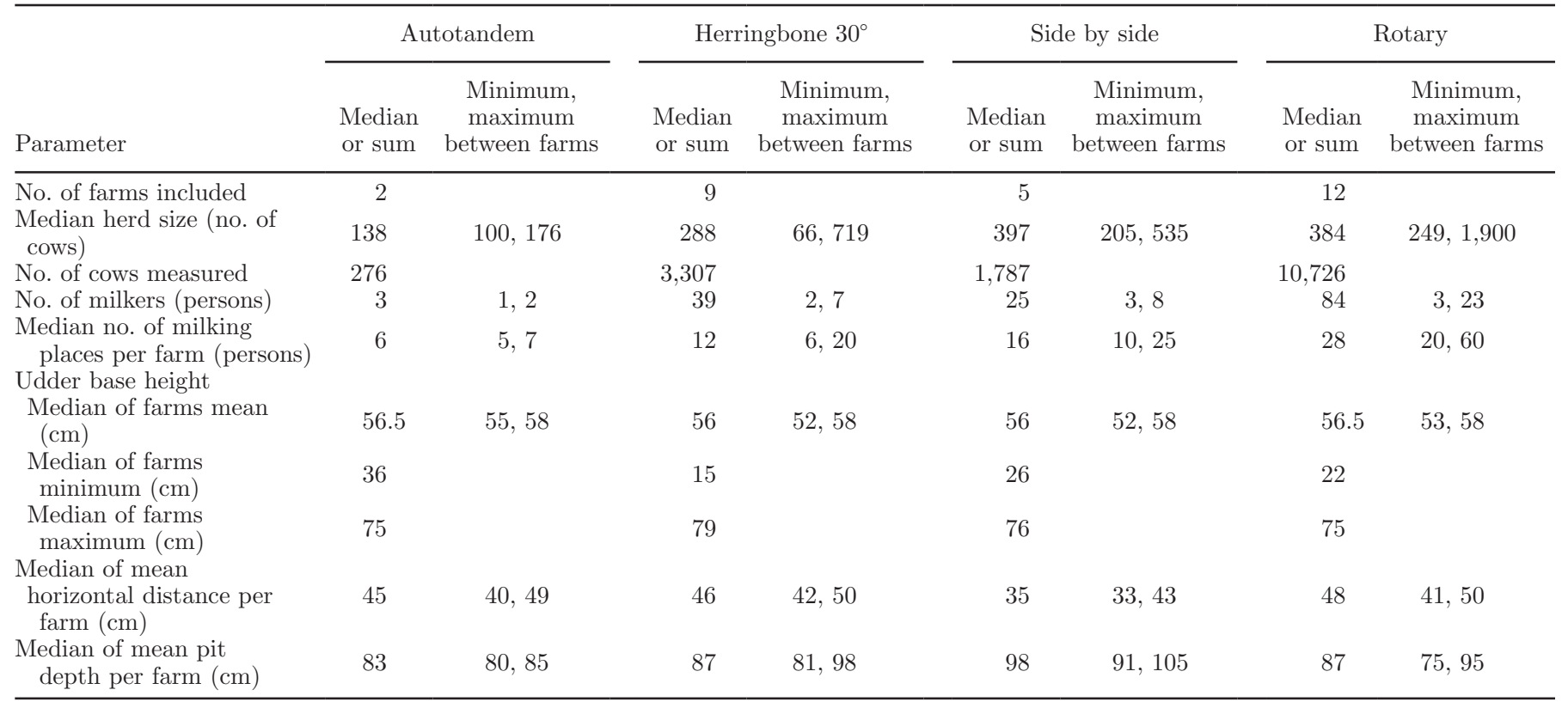

Formula A (OptiPD): ideal pit depth $(\mathrm{cm})=$ shoulder height of the worker $(\mathrm{cm})$ - average udder base height (cm),

Formula B (MHF): ideal pit depth $(\mathrm{cm})=$ individual milker height $(\mathrm{cm}) \times$ parlor-specific constant factor - mean herd udder height $(\mathrm{cm})$.

Formula B multiplies the body height and the constant factors. Therefore, if the ratio between shoulder height and body height (shown in Table 2) equals the parlor-specific constant factor $(0.85$ for autotandem, 0.7 for side by side, 0.75 for rotary, and not provided for herringbone $30^{\circ}$ ), the recommendation is the same for both formulas. Cockburn et al. (2015) published no parlor-specific constant factor for herringbone parlors, and therefore no recommendation is possible here.

\section{Creating the Working Data Set}

The farm data contain all necessary information about the ergonomic characteristics (median of minimum, maximum, and mean pit depth; udder-floor distance, horizontal distance) for every parlor type (autotandem, herringbone $30^{\circ}$, side by side, rotatory). Based on the information, we simulated a workload profile for each of the 4 parlor types, applying formulas A and B for different workers milking in different parlor configurations. The calculation demonstrates the resulting working heights based on the average location of udder height in relation to the shoulder height or if the pit height is adjusted according to recommendations based on formulas $\mathrm{A}$ and $\mathrm{B}$ (referring to the average pit depths). To avoid additional variation attributable to differences in individual anthropometrics of milkers between farms, we used the anthropometrical data of a subject representing the 5 th, 50th, and 95 th percentiles

Table 2. Human body dimensions (in cm) according to DIN/ISO (2005) for subjects aged between 18 and 65 yr

\begin{tabular}{|c|c|c|c|c|c|c|}
\hline \multirow[b]{2}{*}{ Item } & \multicolumn{3}{|c|}{ Male } & \multicolumn{3}{|c|}{ Female } \\
\hline & 5th percentile & 50 th percentile & 95th percentile & 5 th percentile & 50th percentile & 95th percentile \\
\hline Shoulder height $(\mathrm{cm})$ & 134.5 & 145.0 & 155.0 & 126.0 & 134.5 & 142.5 \\
\hline Shoulder height:body height ratio & 0.82 & 0.83 & 0.84 & 0.82 & 0.83 & 0.83 \\
\hline Body height $(\mathrm{cm})$ & 165.0 & 175.0 & 185.5 & 153.5 & 162.5 & 172.0 \\
\hline Forward reach $(\mathrm{cm})$ & 68.5 & 74.0 & 81.5 & 62.5 & 69.0 & 75.0 \\
\hline Depth of body (cm) & 26.0 & 28.5 & 38.0 & 24.5 & 29.0 & 34.5 \\
\hline Net arm length $(\mathrm{cm})$ & 42.5 & 45.5 & 43.5 & 38.0 & 40.0 & 40.5 \\
\hline Elbow-floor distance (cm) & 102.5 & 110.0 & 117.5 & 96.0 & 102.0 & 108.0 \\
\hline
\end{tabular}


of men and women based on the standardized distribution of human body dimensions according to DIN/ISO (2005) for subjects aged between 18 and 65 yr (shown in Table 2). For these subjects in the standard population, we calculated the difference of the mean height of the cow udder in relation to the mean shoulder height considering the 4 parlor types and the 3 working situations (real condition and recommendation according to formulas A and B). Observed mean, minimum, and maximum of herd-specific udder height are included in the calculation to reflect the variation. Table 3 shows the situations found on the visited farms. Table 4 simulates the situation in which we adjust the pit depth according to formula $\mathrm{A}$ and varying anthropometrics. Table 5 simulates the same according to formula B. A negative difference in the results illustrates that the udder is below shoulder level, and a positive difference reflects that the udder is above shoulder level.

Microsoft Excel (Microsoft Corp., Redmond, WA) was used for the calculations. We ran the calculations without statistical tests of the differences between shoulder height and bottom of the udder for men and women and between the parlor types because the calculations are based on percentiles of a standard population, not on real measurements of the population at the workplaces.

\section{Evaluation of Farm Characteristics}

To estimate the occurring workload for milkers, 28 farms with 4 types of parlor systems were visited during a random milking period. Pit floor depth, shoulder height of the workers, and bovimetrics (udder-floor distance and distance between 2 teats) as well as the horizontal distance between the center of the milking cluster and the milker were measured for all animals in lactation on each farm (Figure 1). Table 1 shows the farm characteristics and important parameters for the workplace design.

\section{RESULTS}

\section{Description of Farm Characteristics}

Variables such as udder-floor distance and mean body height of the population of milkers working at the milking parlor are necessary to apply the formulas. The udder-floor distance ranged from 52 to $58 \mathrm{~cm}$ (median $=56.0-56.6 \mathrm{~cm})$ independently of parlor type. The horizontal distance between the center of the claw bowl and the pit edge is significantly smaller in side-byside parlors $(35 \mathrm{~cm})$, where cows stand parallel to each other and perpendicular to the worker. The worker attaches the cluster through the hind legs of the animal.

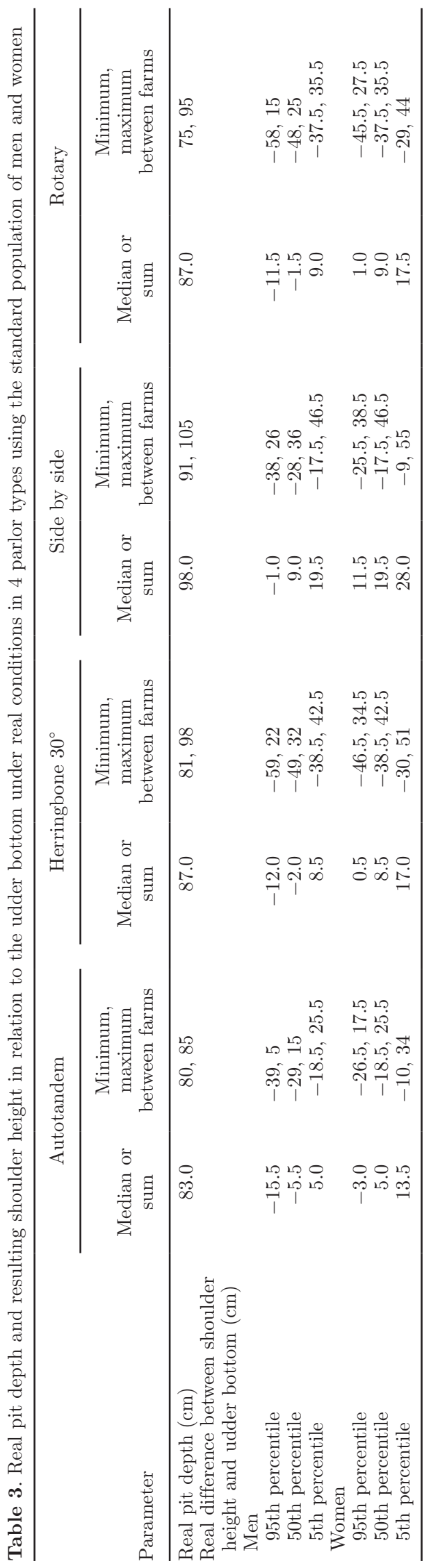



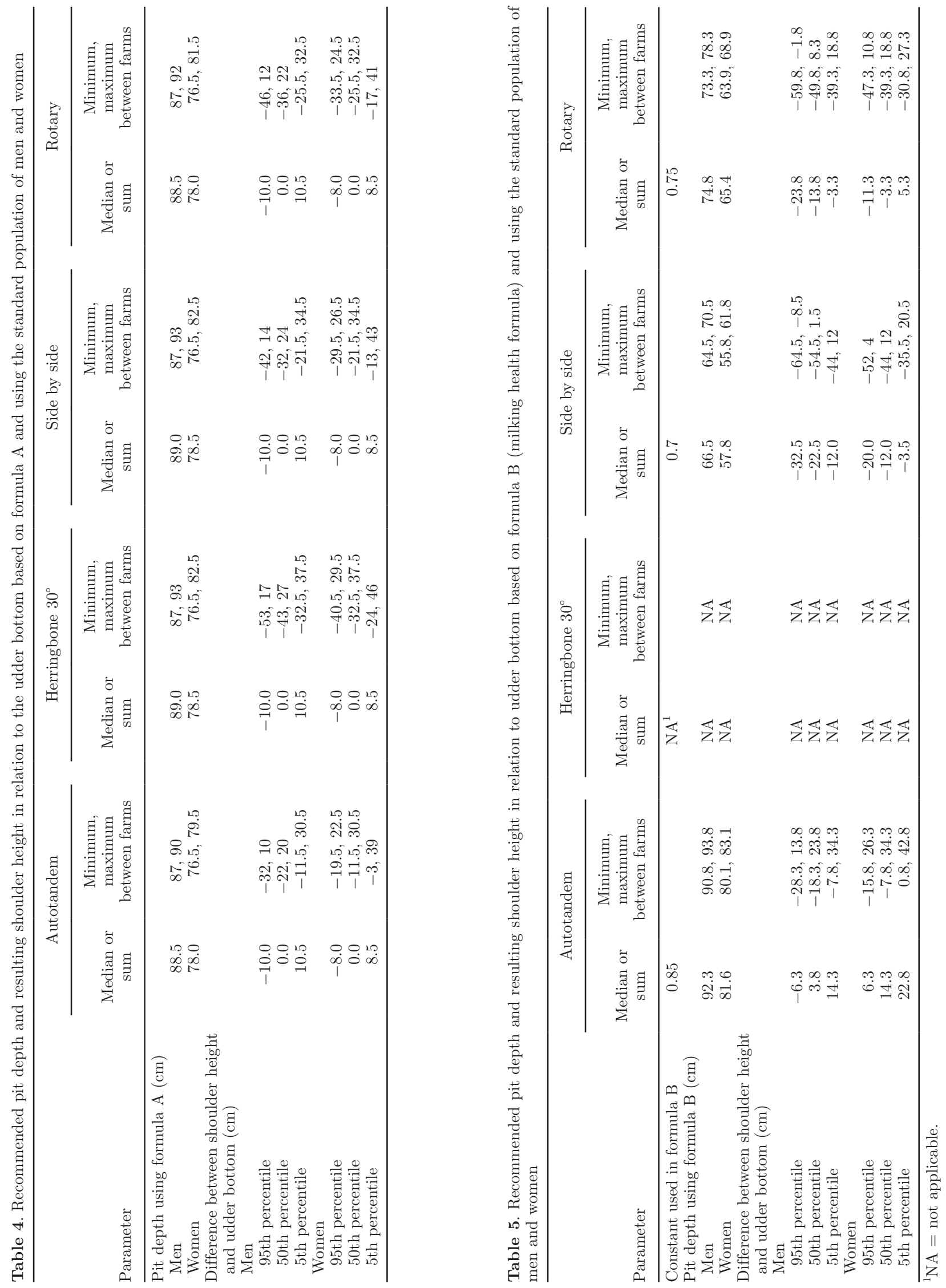
The median of the horizontal distance ranges between 45 and $48 \mathrm{~cm}$ for the other parlor types. The average measured pit depth in autotandem parlors is $83 \mathrm{~cm}$ and in $30^{\circ}$ herringbone and rotary parlors is $87 \mathrm{~cm}$. The deepest pits are found in the side-by-side parlors (average depth $=98 \mathrm{~cm}$; Table 1 ).

\section{Pit Depth and Shoulder Heights Under Real Conditions}

The human body dimensions according to DIN/ISO (2005) were used to simulate the working situation based on the measured parlor characteristics (Table 1). The real working heights for the 5th, 50th, and 95th percentiles of males and females are presented in Table 3.

Assuming that milkers equal the standard population, in autotandem parlors $5 \%$ of all males have to attach the milking cluster at least $5 \mathrm{~cm}$ above shoulder level (average pit depth plus udder-floor distance compared with shoulder height of males based on DIN/ ISO (2005), and $90 \%$ of all males work between $5 \mathrm{~cm}$ above and $15.5 \mathrm{~cm}$ below shoulder level. On average, the udder base is located $5.5 \mathrm{~cm}$ below shoulder level in autotandem parlors for males. For $5 \%$ of female workers the udder is approximately $13.5 \mathrm{~cm}$ or higher above shoulder level, and $90 \%$ encounter an udder height between $13.5 \mathrm{~cm}$ above and $3 \mathrm{~cm}$ below shoulder level. Tall women (95th percentile or taller) have to work about $3 \mathrm{~cm}$ below shoulder level or deeper in autotandem parlors.

In $30^{\circ}$ herringbone parlors, the udder is located between $8.5 \mathrm{~cm}$ above and $12 \mathrm{~cm}$ below shoulder level for $90 \%$ of the males, whereas $90 \%$ of the females work between 0.5 and $17 \mathrm{~cm}$ above shoulder height. Only tall females above the 95th percentile work at least $12 \mathrm{~cm}$ below shoulder level or lower. The same is the case for rotary parlors, as the median of the pit depth equals that of the herringbone parlors.

Because the average pit depth is lower in side-byside parlors, work above shoulder level is more frequent for both males and females. On average, males have to work at least $9 \mathrm{~cm}$ above shoulder level in this parlor type. For tall men ( $\geq 95$ th percentile), the udder base is located approximately at shoulder level $(-1 \mathrm{~cm})$ or lower. Men with a body height below the 5th percentile have to reach up to $19.5 \mathrm{~cm}$ or more to attach the cluster. A pit floor depth of $98 \mathrm{~cm}$ results in constant work above shoulder level (on average $19.5 \mathrm{~cm}$ ) for females based on the average udder-floor distances of the on-farm measurements. Tall females have to reach up $11.5 \mathrm{~cm}$, whereas a short female finds the udder base $28 \mathrm{~cm}$ or higher above her shoulder level based on the herd average. Ninety percent of the standard female population has to work 11.5 to $28 \mathrm{~cm}$ above shoulder level. Regarding the range of udder base heights within the herds, the worst case found was $55 \mathrm{~cm}$ above the shoulder level of the 5 th percentile female.

\section{Shoulder Height and Resulting Pit Depth Applying Formula A}

The purpose of the algorithm behind formula $\mathrm{A}$ is to induce work at shoulder level. Therefore, formula A recommends an ideal pit depth of $89 \mathrm{~cm}$ for the $50 \mathrm{th}$ percentile of males and $79 \mathrm{~cm}$ for the $50 \mathrm{th}$ percentile of females (Table 4). A parlor-specific difference does not apply because the average udder base height was almost the same in all parlor types (Table 1) and depends on the breed, age, and so on of the animal. The recommendation based on formula A would require deeper pits for autotandem parlors $(+5.5 \mathrm{~cm}), 30^{\circ}$ herringbone parlors $(2 \mathrm{~cm})$, and rotatory parlors $(1.5 \mathrm{~cm})$ in this sample to suit the average male. The pit depth in sideby-side parlors has to be reduced by $9 \mathrm{~cm}$ for males.

Following the recommendation of formula A to work at shoulder level, $90 \%$ of all men would work $10.5 \mathrm{~cm}$ above and $10 \mathrm{~cm}$ below shoulder level independent of the parlor type. For $90 \%$ of the females, the bottom of the udder would be between $8.5 \mathrm{~cm}$ above and $8 \mathrm{~cm}$ below shoulder level.

\section{Shoulder Height and Resulting Pit Depth Applying Formula $B$}

According to formula $\mathrm{B}$, the pit depth in autotandem parlors is about $9 \mathrm{~cm}$ too deep, and in rotary parlors it is $31 \mathrm{~cm}$ and in side-by-side parlors it is $12 \mathrm{~cm}$ deeper than recommended (Table 5). It is not possible to apply formula B to simulate the working height for $30^{\circ}$ herringbone parlors.

In autotandem parlors, the recommended depth of $92 \mathrm{~cm}$ for an average male differs by $9 \mathrm{~cm}$ from the farm average of $83 \mathrm{~cm}$ shown in Table 1. If the recommendation based on formula B is implemented in this parlor type, men work on average almost $4 \mathrm{~cm}$ above shoulder height. Short men (below the 5th percentile of human body height) have to work $14 \mathrm{~cm}$ or higher above their shoulder height. Tall men (95th percentile or taller) encounter an udder about $6 \mathrm{~cm}$ below their shoulder height or lower. If the largest cow meets the 5 th percentile female, the udder may be $43 \mathrm{~cm}$ above shoulder level, but if the tallest percentile male meets an old cow in a side-by-side parlor adjusted according to formula $\mathrm{B}$, the udder can be $65 \mathrm{~cm}$ below shoulder level. 
Considering side-by-side parlors, there is a big difference between recommendations according to formula $\mathrm{B}$ and the observed pit depth. The pit depth should be adjusted to $67 \mathrm{~cm}$ for males and $58 \mathrm{~cm}$ for females in contrast to the observed average pit depth of $98 \mathrm{~cm}$ shown in Table 1 . On average (the 50th percentile), men have to work $32 \mathrm{~cm}$ below shoulder level and women have to work $12 \mathrm{~cm}$ below shoulder level. Even short men or women (shorter than the 5th percentile) have to work 12 or $4 \mathrm{~cm}$ below shoulder level, respectively. Tall men and women (taller than the 95th percentile) find the udder 32 or $20 \mathrm{~cm}$ below shoulder level, respectively, or lower.

If rotary parlors would be redesigned using formula B, $95 \%$ of men and almost $50 \%$ of women would work 3 $\mathrm{cm}$ below shoulder level or lower. On average, men work $14 \mathrm{~cm}$ below shoulder level in this scenario. The udder is placed $24 \mathrm{~cm}$ or deeper for very tall men $(\geq 95$ th percentile). Only very tall women ( $\geq 95$ th percentile) would work $11 \mathrm{~cm}$ below shoulder level or lower. For $90 \%$ of all women the udder is located almost at shoulder level (between $11 \mathrm{~cm}$ below and $5 \mathrm{~cm}$ above).

The assessed anthropometrics of the milkers working on the farms allow the assumption that they do not significantly differ from the standard population used. However, because the collected sample is not representative, it was not used.

\section{DISCUSSION}

This simulation compares the differences between 2 recommendations available for determining the proper pit depth based on a large set of cow biometric data (bovimetrics), the description of milking parlors, and the given standardized distribution of human body dimensions. The main result is that milkers have to work at shoulder level independently of the type of milking parlor if formula $\mathrm{A}$ is applied. Considering formula $\mathrm{B}$, the mean working height is predominantly below shoulder level, and the recommendation depends on the milking parlor type.

The need to discuss the problem of working height in milking parlors and the necessity of ergonomic interventions is driven by the continuously high rate of musculoskeletal symptoms among parlor workers worldwide. The literature review for recommendations regarding pit depth brought up rather imprecise information. Following Vos (1974), the height of the platform or pit depth is of great importance and needs precise recommendations. A guide for the prevention of musculoskeletal disorders named "Milking Cows" (IDEWE, 2014) advises the use of adjustable floors and light milking clusters; precise adjustment for the floors is not described.
A Canadian fact sheet (House, 2015) states the following: "The recommended pit depth varies with operator height and parlor design. Operators should not have to bend or stoop during milking. Deeper pits improve udder visibility and availability. The optimum working area lies between the elbow and the shoulder, an area of about $30.5 \mathrm{~cm}$. The base of the udder should be located between these points, when the operator is comfortably standing. The elbows of the operator should not contact the cow platform." Table 2 displays human body dimensions. According to the fact sheet and Table 2, the udder base should be located ideally between 126 and $96 \mathrm{~cm}$ from ground level for the 5th percentile female and between 155 and $117.5 \mathrm{~cm}$ from ground level for the 95th percentile male regardless of the milking parlor type. The average distances between floor and udder base described in Table 1 ranged between 52 and $58 \mathrm{~cm}$. Using these numbers to calculate the optimal pit depth, a short female requires a pit depth between 41 and $71 \mathrm{~cm}$ ( $55 \mathrm{~cm}$ udder base-floor distance), and a large male requires a pit depth between 62.5 and $100 \mathrm{~cm}$. The described common pit depths in Canadian parlors (House, 2015) would suit large males if the pits are not deeper than $100 \mathrm{~cm}$. To avoid repeated and frequent stooping with short recovery time (ISO, 2000), milking below shoulder level should be avoided. Jakob et al. (2012) measured an average angle of $15^{\circ}$ for trunk inclination if the cluster has to be attached $20 \mathrm{~cm}$ below shoulder level. According to those measurements, allowing a range of $30 \mathrm{~cm}$ would not prevent stooping.

Formula A was a result of a complex workload assessment comparing different evaluation criteria in 3 different working heights in a laboratory setting. The working heights induced typical kinematic patterns for different body parts, and therefore it was impossible to find the ideal setting for all muscle groups and joints. The most favorable situation was selected from a blend of parameters that were ranked over all experimental settings, including work above, at, and below shoulder level (Jakob et al., 2012). Jakob et al. (2012) recommend work at shoulder level regarding the relatively low individual workload compared with the other work postures. In their study, work below shoulder height is rated most tiring by subjective evaluation (the Borg scale). This gives rise to the consideration that formula $\mathrm{B}$ is not optimal for side-by-side and rotary parlors.

Formula B was developed by modeling the results of a full shift motion analysis in real dairy parlors observing a significant interaction between parlor and worker kinematics. This is comparable with the ranking system, but the measured joints were the only evaluation criteria for the selection of the optimal settings (Cockburn et al., 2015) in comparison with several parameters in the aforementioned study by Jakob et al. (2012). 
In both studies, anthropometrics and udder-floor distance are known. For the development of formula B the horizontal distance was variable and not measured during the recording of body postures, whereas for the development of formula A a distance of $40 \mathrm{~cm}$ was fixed during the whole experiment. Thinius and Jakob (2014) found a large variation in the horizontal distance, and it often exceeded the net reach of the workers (Tables 1 and 2); this will have a significant effect on body posture. It is impossible to differentiate between the effects of the horizontal distance and the vertical distance on body posture if the value varies, as is the case for the study creating formula B. Cockburn et al. (2015) state that their formula indirectly reflects the horizontal distance by considering the body height of the milker and the udder height. They assume a larger distance for side-by-side parlors, referring to Douphrate et al. (2014) and Tuure and Alasuutari (2009); this explains the larger parlor-specific constant factor for side-byside configurations. Tuure and Alasuutari (2009) report a horizontal distance of $45 \mathrm{~cm}$ for herringbone parlors $\left(30^{\circ}\right)$, which supports the results shown in Table 1 . The sample size of Tuure and Alasuutari (2009) was 18 cows compared with 3,687 cows in the study of Thinius and Jakob (2014), who found a significantly shorter horizontal distance between the udder and the worker for the side-by-side parlors; this most likely is explained by self-indexing exit gates commonly installed in this parlor type. A shorter horizontal distance is also supported by Goméz et al. (2017), where the space ratio (length of parlor by length of animal) for cows in milking parlors is described and side-by-side parlors showed the smallest ratio. Douphrate et al. (2014) propose a longer reach for side-by-side and outside rotaries, but the data set has no statistical evidence. Cockburn et al. (2015) did not measure the horizontal reaching distance, whereas Douphrate et al. (2014) describe measuring a few parlor structural characteristics such as the distance from the pit edge to the center of the cow udder. Douphrate et al. (2014) give no information about the precise measurement or the sample size, and statistical evidence for differences between parlor types is missing. Thinius and Jakob (2014) showed that there is a large variation within 1 farm, which makes it necessary to measure the complete herd or at least a representative sample. Finally, the American study comprises farms with herd sizes between 680 and 6,000 cows. The Swiss study does not mention herd sizes, but farms in this region are much smaller. Therefore, a conclusion that side-by-side parlors are equivalent in both studies seems to be unreliable. The horizontal gap between worker and animal influences the workload, and no research on that aspect is available. Further research based on field studies as well as experimental laboratory studies is therefore necessary to be able to estimate the influence of the horizontal gap on both formulas.

A comparison of the worker height and pit depth used in the experimental setting for the development of formula B concludes that the pit floors were ideal for the workers in all situations apart from the sideby-side parlor, assuming that work at shoulder height is best. For the side-by-side parlor, the worker should have been taller. If one calculates the recommended pit depth according to formula $\mathrm{B}$, none of the parlors would have had an ideal pit depth. No statement is possible for $30^{\circ}$ herringbone parlors because the parlorspecific constant factor is not specified in the reference.

The biggest change between the existing situation and the recommendation would become necessary in the side-by-side parlors. A reduction of $30 \mathrm{~cm}$ for the 50th percentile male was calculated using formula B. According to the German sample collected by Thinius and Jakob (2014), side-by-side parlors have the deepest pits. Cockburn et al. (2015) stated the same, with depths similar to the German sample, and Douphrate et al. (2014) measured even deeper pits for US dairy parlors. No explanation for the deeper pits in side-by-side parlors can be found in the literature. An explanation might be indirectly given by House (2015), who states that a deeper pit increases the visibility of the udder. Side-by-side parlors are mostly equipped with shields protecting the worker from the manure, which reduces the visibility of the udder. The positioning of the cow also reduces the visible area of the cow. As a consequence, the parlor designers might have chosen the deeper pits. Table 3 shows that sideby-side parlors suit only the 95th percentile male in their existing form. Being shorter than recommended means that most of the udders will be located above shoulder height. Depending on the extent, this means high loads for the muscles of the upper extremities (van der Windt et al., 2000; Mayer et al., 2012; Shin and Yoo, 2015).

The difference between formulas A and B is based on the parlor-specific constant factor. Table 2 shows the relationship between body height and shoulder height. If the parlor-specific constant factor equals this ratio, there is no difference between the 2 formulas; this is almost the case for autotandem parlors. No specification was yet made for the parlor-specific constant factor for $30^{\circ}$ herringbone parlors. If side-by-side and rotary parlors are constructed according to formula B, there will be little work above shoulder level, but most of the udders will be located below shoulder level. This unfortunately requires milkers to work more frequently with a bent back and is related to higher biomechanical demands on the back muscles and the spine. 
Considering both recommendations, none of the parlors on the farms visited were ideal for the average female. Side-by-side parlors suit only the 95 th percentile male and therefore should be redesigned in the future with priority.

For large herds, rotary parlors are the most common system. Big rotary parlors are constructed as outside rotaries, where cows are situated parallel to each other. None of the parlors in the German sample was an outside rotary, so no information on common pit depths or horizontal distances between udder and worker is available. Cockburn et al. (2015) did not publish a parlor-specific constant factor for this parlor type either. The work routine on large farms is coupled with increasing task specialization and work demands, such as high repetition, little job variation, awkward postures, and little time for rest. The more time workers spend milking, the more important it is to have an adequate working height.

\section{CONCLUSIONS}

So far, a precise guideline for the adjustment of the pit depth is missing. The comparison of the 2 recently published formulas resulted in strong differences for the side-by-side and inside rotary parlor types. The actual design of side-by-side parlors strongly differs from the recommendations according to both formulas. Adjustments for those parlor types according to formula B result in work below shoulder level. More attention needs to be paid to the horizontal gap between the animal and the worker, which often exceeds the net reach of the workers. If the height is not optimal, excessive reach makes work even more strenuous. Before building a new parlor, measuring the animals as well as the work force is necessary for precisely calculating the pit depth. In running parlors, a regular risk assessment of the workplaces is necessary. Additionally, occupational health care could be offered.

\section{ACKNOWLEDGMENTS}

We thank the farmers and milkers involved for their support and cooperation. The study is part of the research supported by the Leibniz-Institute for Agricultural Engineering and Bioeconomy (ATB) in cooperation with the Federal Institute for Occupational Health and Safety (BAUA Berlin).

\section{REFERENCES}

Auernhammer, H. 1987. Wie schwer ist Melkarbeit? DLG-Mitteilungen. 23:1234-1237.

Cockburn, M., P. Savary, M. Kauke, M. Schick, U. Hoehne-Hückstädt, I. Herrmanns, and R. Ellegast. 2015. Improving ergonomics in milking parlors: Empirical findings for optimal working heights in five milking parlor types. J. Dairy Sci. 98:966-974.

da Costa, B. R., and E. R. Vieira. 2010. Risk factors for work-related musculoskeletal disorders: A systematic review of recent longitudinal studies. Am. J. Ind. Med. 53:285-323.

DIN/ISO. (Deutsches Institut für Normung/International Organization for Standardization). 2005. Ergonomics - Human body dimensions-Part 2: Values. Standard number 33402-2:2005-12. DIN, Berlin, Germany, and ISO, Geneva, Switzerland.

DIN/ISO. (Deutsches Institut für Normung/International Organization for Standardization). 2009. Safety of machinery-Human physical performance - Part 4: Evaluation of working postures and movements in relation to machinery. Standard number 10054:2009-01. DIN, Berlin, Germany, and ISO, Geneva, Switzerland.

DIN/ISO. (Deutsches Institut für Normung/International Organization for Standardization). 2016. Ergonomics principles in the design of work systems. Standard number 6385:2016-12. DIN, Berlin, Germany, and ISO, Geneva, Switzerland.

Douphrate, D. I., D. Gimeno, M. W. Nonnemann, R. Hagevoort, C. Rosas-Goulart, and J. C. Rosecrance. 2014. Prevalence of work-related musculoskeletal symptoms among US large-herd dairy parlor workers. Am. J. Ind. Med. 57:370-379.

Douphrate, D. I., M. W. Nonnemann, and J. C. Rosecrance. 2009. Ergonomics in industrialized dairy operations. J. Agromedicine $14: 406-412$.

Eurofound. 2012. Milking cows - Good practices in agriculture: Social partners participation in the prevention of musculoskeletal disorders. Accessed Sep. 20, 2016. http://www.agri-ergonomics.eu/ downloads/PDF/Summary/milking_cows_LR.pdf.

Goméz, Y., M. Terranova, M. Zähner, E. Hillman, and P. Savary. 2017. Effects of milking stall dimensions on behavior of dairy cows during milking in different milking parlor types. J. Dairy Sci. 100:1331-1339.

Graf, K. 2005. Untersuchungen von Zusammenhängen zwischen morphologischen Merkmalen des Euters, der Eutergesundheit und melktechnischen Parametern bei Tieren der Rasse Deutsches Holstein. Dissertation. Martin Luther University of Halle-Wittenberg, Germany.

House, H. 2015. Dairy housing - Milking centre design and construction for parlour milking. Accessed Jul. 6, 2016. http://www.omafra.gov. on.ca/english/engineer/facts/15-021.htm.

IDEWE. 2014. Milking cows - Good practices in agriculture: Social partners participation. IDEWE External Service for Prevention and Protection at Work, Leuven, Belgium. Accessed Sep. 20, 2016. http://www.agri-ergonomics.eu/good_practices/good_practices/ milking_cows_files/milking_cows_LR.pdf.

ISO (International Organization for Standardization). 2000. Ergonomics - Evaluation of static working postures. Standard number 11226:2000. ISO, Geneva, Switzerland.

ISO (International Organization for Standardization). 2002. Safety of machinery-Anthropometric requirements for the design of workstations at machinery. Standard number 14738:2002. ISO, Geneva, Switzerland.

Jakob, M., and F. Liebers. 2011. Potential of a quarter individual milking system to reduce the workload in large-herd dairy operations. J. Agromedicine 16:280-291.

Jakob, M., F. Liebers, and S. Behrendt. 2012. The effects of working height and manipulated weights on subjective strain, body posture and muscular activity of milking parlor operatives-Laboratory study. Appl. Ergon. 43:753-761.

Kauke, M., F. Korth, P. Savary, and M. Schick. 2010. Workload in modern dairy farms - Assessment from the user's perspective. Pages 1-4 in Proceedings of CIGR XVIIth World Congress. CIGR, Québec City, Canada.

Kuorinka, I., B. Jonsson, A. Kilbom, H. Vinterberg, F. Biering-Sorensen, G. Andersson, and K. Jorgensen. 1987. Standardised Nordic questionnaires for the analysis of musculoskeletal symptoms. Appl. Ergon. 18:233-237.

Liebers, F., C. Brendler, and U. Latza. 2016. Berufsspezifisches Risiko für das Auftreten von Arbeitsunfähigkeit durch Muskel-SkelettErkrankungen und Krankheiten des Herz-Kreislauf-Systems- 
Bestimmung von Berufen mit hoher Relevanz für die Prävention. Federal Institute for Occupational Safety and Health, Berlin, Germany.

Lunner Kolstrup, C. 2012. Work-related musculoskeletal discomfort of dairy farmers and employed workers. J. Occup. Med. Toxicol. 7:23.

Lunner Kolstrup, C., and M. C. Jakob. 2016. Epidemiology of musculoskeletal symptoms among milkers and dairy farm characteristics in Sweden and Germany. J. Agromedicine 21:43-55.

Martens, H., and C. Bange. 2013. Longevity of high producing dairy cows: A case study. Lohmann Information 48:53-57.

Masci, F., A. Mixco, C. A. Brents, L. Murgia, C. Colosio, and J. Rosecrance. 2016. Comparison of upper limb muscle activity among workers in large-herd U.S. and small-herd Italian dairies. Front. Public Health 4:141. https://doi.org/10.3389/fpubh.2016.00141.

Mayer, J., T. Kraus, and E. Ochsmann. 2012. Longitudinal evidence for the association between work-related physical exposures and neck and/or shoulder complaints: A systematic review. Int. Arch. Occup. Environ. Health 85:587-603.

ÖKL-Arbeitskreis Landwirtschaftsbau. 2015. ÖKL-Merkblatt 51 Melkstandanlagen. Österreichisches Kuratorium für Landtechnik und Landentwicklung - ÖKL, Wien, Austria.
Pinzke, S. 2003. Changes in working conditions and health among dairy farmers in southern Sweden. A 14-year follow-up. Ann. Agric. Environ. Med. 10:185-195.

Pinzke, S. 2016. Comparison of working conditions and prevalence of musculoskeletal symptoms among dairy farmers in southern Sweden over a 25-year period. Front. Public Health 4:98.

Shin, S. J., and W. G. Yoo. 2015. Effects of overhead work involving different heights and distances on neck and shoulder muscle activity. Work 51:321-326.

Thinius, M., and M. C. Jakob. 2014. Ergonomic workplace evaluation and epidemiology of musculoskeletal discomfort on German dairy farms. Work 49:25-32.

Tuure, V. M., and S. Alasuutari. 2009. Reducing work load in shoulder-neck region in parlor milking. Bornimer Agrartechnische Berichte. 66:48-54.

van der Windt, D. A., E. Thomas, D. P. Pope, A. F. de Winter, G. J. Macfarlane, L. M. Bouter, and A. J. Silman. 2000. Occupational risk factors for shoulder pain: A systematic review. Occup. Environ. Med. 57:433-442.

Vos, H. W. 1974. Some ergonomic aspects of parlour milking. Can Agric. Eng. 16:45-48. 